\section{Spectral Changes in Metal Halide and High-pressure Sodium Lamps Equipped with Electronic Dimming}

\author{
David L. Bubenheim ${ }^{1}$, Raman Sargis ${ }^{2}$, and David Wilson ${ }^{2}$ \\ National Aeronautics and Space Administration Ames Research Center, \\ Advanced Life Support Division, Regenerative Systems Branch, Moffett Field, \\ CA 94035
}

Additional index words. controlled environments, growth chambers, lighting systems, photobiology, photosynthetic photon flux

\begin{abstract}
Electronic dimming of high-intensity discharge lamps offers control of photosynthetic photon flux (PPF) but is often characterized as causing significant spectral changes. Growth chambers with 400-W metal halide (MH) and high-pressure sodium (HPS) lamps were equipped with a dimmer system using silicon-controlled rectifiers (SCR) as highspeed switches. Phase control operation turned the line power off for some period of the alternating current cycle. At full power, the electrical input to HPS and MH lamps was 480 $\mathrm{W}$ (root mean squared) and could be decreased to $267 \mathrm{~W}$ and $428 \mathrm{~W}$, respectively, before the arc was extinguished. Concomitant with this decrease in input power, PPF decreased by $60 \%$ in HPS and $50 \%$ in MH. The HPS lamp has characteristic spectral peaks at 589 and $595 \mathrm{~nm}$. As power to the HPS lamps was decreased, the 589-nm peak remained constant while the 595-nm peak decreased, equaling the 589-nm peak at 345-W input, and the 589-nm peak was almost absent at 270-W input. The MH lamp has a broader spectral output but also has a peak at $589 \mathrm{~nm}$ and another smaller peak at $545 \mathrm{~nm}$. As input power to the MH lamps decreased, the peak at 589 diminished to equal the $545-\mathrm{nm}$ peak. As input power approached $428 \mathrm{~W}$, the $589-\mathrm{nm}$ peak shifted to $570 \mathrm{~nm}$. While the spectrum changed as input power was decreased in the MH and HPS lamps, the phytochrome equilibrium ratio $\left(P_{f r}: P_{t o t}\right)$ remains unchanged for both lamp types.
\end{abstract}

Control of photosynthetic photon flux (PPF) in controlled-environment plant growth chambers often presents many obstacles (Bubenheim et al., 1988; Downs, 1975; McFarlane, 1978). As plant height increases during growth, lamp height must be adjusted, plants lowered, or filters placed between lamps and plants to maintain a specific flux at the top of the canopy. An alternative method to PPF control is electronic dimming of the lamps by reducing power input. Dimming of lamps offers several clear advantages; however, dimming systems are costly and approaches that alter arc characteristics of high-intensity discharge (HID) lamps result in spectral output. Use of siliconcontrolled rectifiers (SCR) as high-speed switches to maintain arc integrity while decreasing power delivered to lamps represents growth chambers.

Received for publication 4 July 1994. Accepted for publication 12 Oct. 1994. This research was supported by the National Aeronautics and Space Adtrademark, proprietary product, or vendor does not constitute a guarantee or warranty of the product and does not imply its approval to the exclusion of other products or vendors that also may be suitable. The cost of publishing this paper was defrayed in part by the payment of page charges. Under postal regulations, this paper therefore must be hereby marked advertisement solely to indicate this fact.

${ }^{1}$ To whom reprint requests should be addressed. ${ }^{2}$ Bionetics Corp., Ames Research Center, Advanced Life Support Division, Regenerative Systems Branch, Moffett Field, CA 94035. a relatively new technology available for plant ministration, RTOP \#199-61-12-20. Mention of a ing ballasts by delivering power to lamps in small bursts. Since real electronic switches are not perfect, some deficiencies do exist and electronic ballasts perform at $<100 \%$ efficiency. Although electronic switching ballasts are less than perfect, they still maintain a higher level of operational efficiency than linear ballasts, in which a large amount of power is dissipated within the ballast. Since the output of the linear ballast is constant, decreasing the power delivered to a lamp results in decreased operating arc temperature, thus possibly changing the spectral distribution. An electronic switching ballast should more effectively maintain arc temperature with short bursts at full power. The switching ballast should provide a more stable output than the linear ballast system.

In addition to the switching feature of the Macro HID dimmers (MacroElectronics Corp., Austin, Texas) used in this study, they have several other desirable features that are important characteristics of any effective dimming system. When the lamps are first energized, the dimmer automatically supplies full power, regardless of the dimming setting, allowing the arc tube to reach optimum operating temperature before responding to the dimming set point. Also, the system continuously monitors input line voltage and operates as a line voltage regulator by automatically compensating for changes in input line voltage.

The purposes of this study were to quantify the effectiveness of SCR electronic dimming in controlling PPF with metal halide (MH) and high-pressure sodium (HPS) HID lamps, to characterize any spectral changes associated with this method of dimming, and to assess the potential influence of any resulting spectral changes on plant physiology or morphology by monitoring phytochrome equilibrium ratios.

\section{Materials and Methods}

Growth chamber and lighting system. An Environmental Growth Chamber Corp. (Chagrin Falls, Ohio) model M-12 growth chamber was used for all testing. The chamber has interior dimensions of $1.2 \mathrm{~m}$ wide $\times 0.9 \mathrm{~m}$ deep

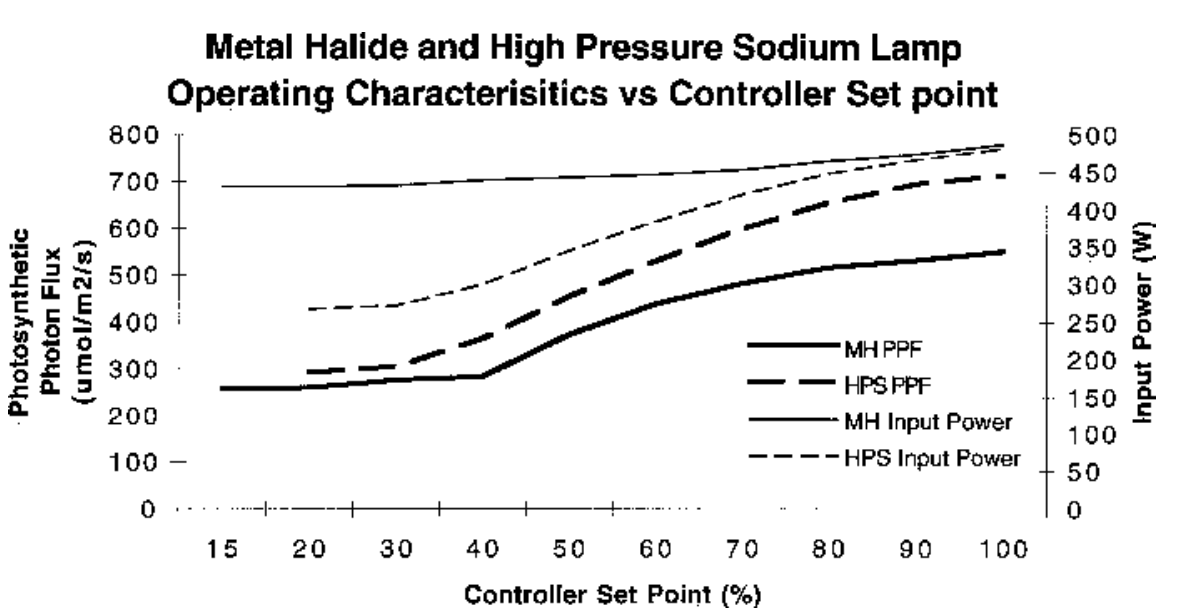

Fig. 1. Photosynthetic photon flux and input power to metal halide (MH) and high-pressure sodium (HPS) lamps as a function of variable voltage ballast controller set point. 
$\times 1.2 \mathrm{~m}$ high; the interior walls of the chamber are polished aluminum. The custom lighting system consists of 12 HID, six 400-W HPS, and six 400-W MH lamps. The horizontally mounted lamps are alternately positioned in three rows of four to provide uniform irradiance from each lamp type, and each lamp is mounted in a polished aluminum reflector. The lamp bank assembly is suspended above a sheet of tempered glass with a 5-cm layer of water flowing over the glass to minimize nonphotosynthetic radiation entering the growth volume. The glass and water layer do not modify the radiation transmitted in the spectral range considered in this study (Bubenheim et al., 1988). The HPS and MH lamps can be powered independently or in combination.

HID dimming system. The HID dimmer operates by using SCRs as high-speed switches, in a phase control operation, to turn the alternating current $(\mathrm{AC})$ line input power off during specified portions of the AC cycle; for full bright operation the on time is near to $100 \%$. As off time is increased (duty cycle decreased), power to the ballast is lessened, thus less power is delivered to the HID arc tube, resulting in lower lamp output. When the SCR is off, it is fully off and no power is supplied to the ballast and lamp. If the switch remains off for too long, the arc of the HID lamp will extinguish; to extend the dimming range to provide low light levels, a separate circuit provides a small amount of current to the ballast and lamp while the SCRs are off for extended periods. We monitored line voltage to individual lamps using a multimeter capable of making true root mean squared (RMS) measurements.

Spectral measurements. The radiation environment was characterized over the 300- to 800-nm range at 5-nm steps with 30 samples per step using an EG\&G Gamma Scientific (San Diego) spectroradiometer: model GS4100 radiometer, NM-3DH monochrometer, RS-10 standard lamp, D-46AQ photomultiplier and fiber optic tube with miniature cosine corrector as the receiver. The radiometer equipment was maintained outside of the growth chamber. The fiber optic cable entered the chamber and the distance from the receiver to the glass ceiling was maintained at $80 \mathrm{~cm}$ (distance to the lamps remained constant as well).

The spectral quality of HPS and MH output was characterized over the full dimmer range, $100 \%$ to arc extinguished, at $5 \%$ power input steps. The HPS and MH lamps were powered to the $100 \%$ setting and maintained there for 30 min. Following this warm-up period, the controlled setting was either reduced in 5\% steps or the controller set points were randomly selected. The sequential down stepping and random controller setting approaches were repeated six times per lamp type, and lamps were allowed to equilibrate for $10 \mathrm{~min}$ at a set point before recording the spectral quality.

Because it was impractical to monitor the input voltage to each individual lamp simultaneously when the lamp bank was energized, we choose to report single lamp data where true RMS input wattage could be measured accurately. We were able to monitor the input to two lamps simultaneously and were thus able to characterize the combined HPS and MHradiation environment. Variability among lamps of the same type was estimated by testing three individual lamps of each type over the full dimmer range, using the same fixture and reflector assembly. Data presented characterizing the variability in spectral quality, PPF, total energy output, and phytochrome equilibrium ratio observed among three lamps of the same type are for a 55\% input controller set point, which corresponds to 365 and $445 \mathrm{~W}$ for the HPS and MH lamps, respectively.

Potential influence of any spectral changes associated with dimming of HPS and MH lamps was estimated by calculating the phytochrome equilibrium ratio $\left(\mathrm{P}_{\mathrm{fr}}: \mathrm{P}_{\text {tot }}\right)$ established in each radiation environment. The absorption coefficients used in these calculations were those published by Sager et al. (1986).

\section{Results}

No difference could be detected in spectral quality following random selection of the controller set point or sequentially stepping down from $100 \%$ to $20 \%$; the data presented are a combination of both approaches. Data are

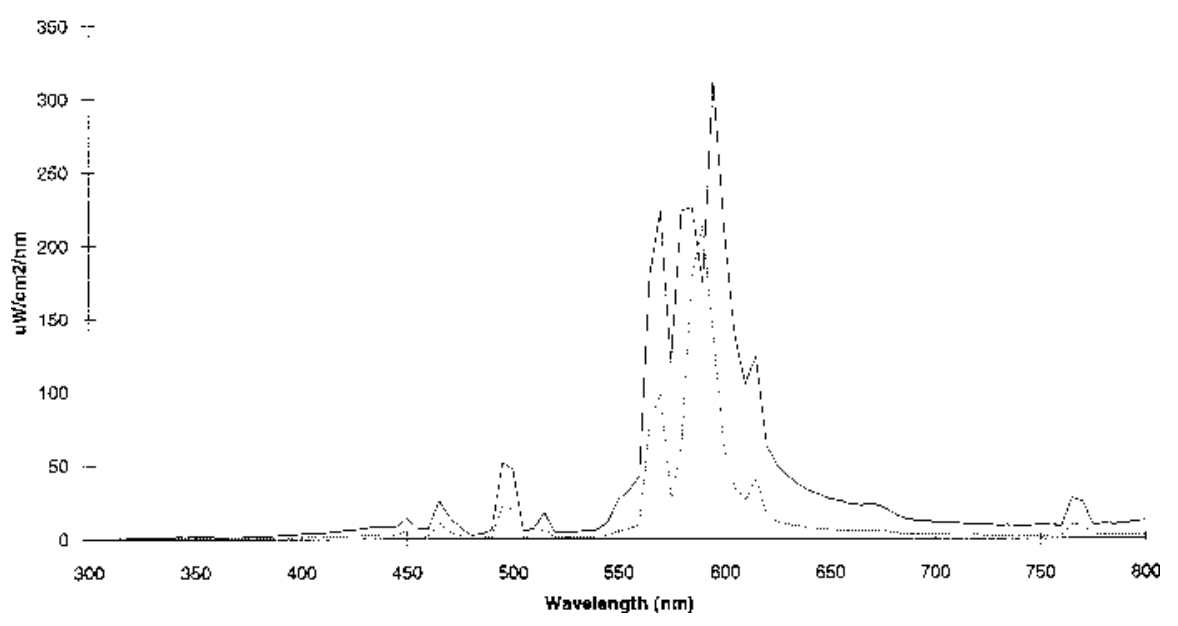

Fig. 2. Spectral quality resulting from operation of high-pressure sodium lamps at full input power $(-, 480$ W) or minimum power (------, $267 \mathrm{~W})$.

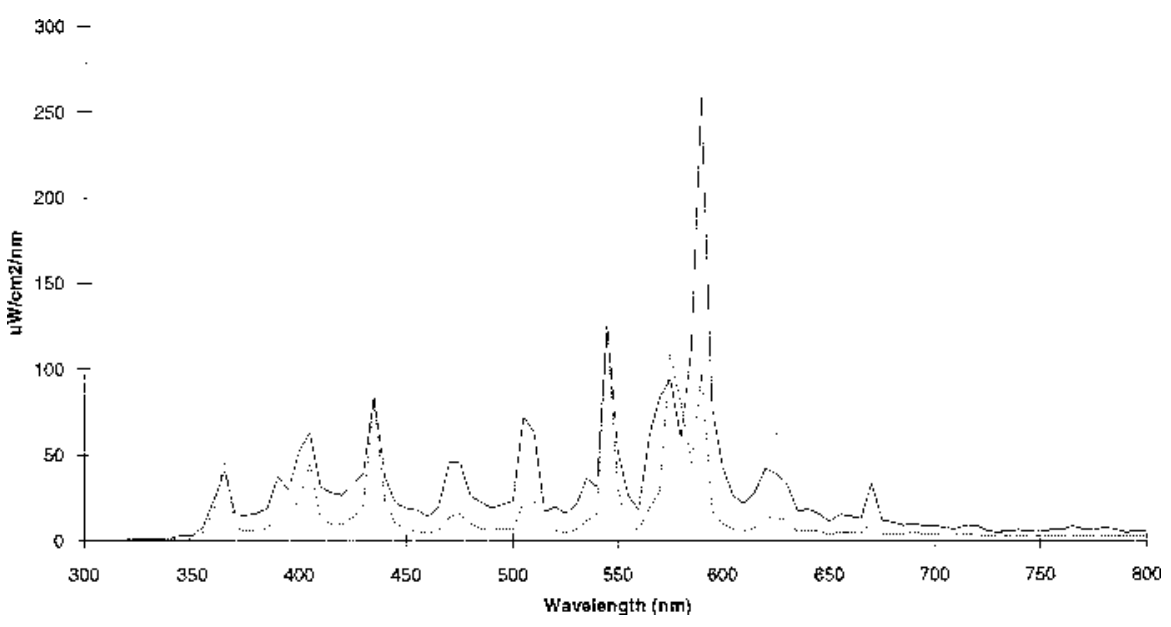

Fig. 3. Spectral quality resulting from operation of metal halide lamps at full input power $(-, 480 \mathrm{~W})$ or minimum power (-----, $428 \mathrm{~W})$. presented for single HPS and MH lamps. The same qualitative results were obtained with single lamps and lamp bank, only the absolute energy levels were greater with the lamp bank compared with a single lamp.

At full power the electrical input to HPS and MH lamps was 480 and 487 W (RMS), respectively, and was decreased to 267 and $428 \mathrm{~W}$ before the arc was extinguished (Fig. 1). Concomitant with this decrease in input power, PPF decreased by $60 \%$ in HPS and $50 \%$ in MH. In the HPS environment, PPF gradually decreased from 714 to 292 $\mu \mathrm{mol} \cdot \mathrm{m}^{-2} \cdot \mathrm{s}^{-1}$ and from 551 to $259 \mu \mathrm{mol} \cdot \mathrm{m}^{-2} \cdot \mathrm{s}^{-1}$ with the MH lamps. The efficiency of the lamp/reflector configuration in this chamber provided an electrical efficiency (photosynthetic energy delivered to the growing plane/ input wattage) of $30 \%$ with the HPS and $23 \%$ with the MH lamps. The delivered efficiency HPS and MH as input wattage was decreased to the minimum.

The HPS lamp has characteristic spectral peaks at 589 and $595 \mathrm{~nm}$ (Fig. 2). At full input power of $480 \mathrm{~W}$, the peak at $589 \mathrm{~nm}$ is $17 \%$ smaller than the 595 peak. As power to the HPS lamps was decreased, the 589-nm peak remained constant while the 595-nm peak dedecreased to $22 \%$ and $12 \%$, respectively, for 
creased, equaling the 589-nm peak at $345-\mathrm{W}$ input. The 595- and 589-nm peaks had almost completely collapsed at $270-\mathrm{W}$ input, and a single dominant peak remained at $591 \mathrm{~nm}$, the previous trough between the 589- and 595-nm peaks. Some energy was still present at 589and 595-nm wavelength just before the arc extinguishing. The small peaks in the blue region remained and retained relative heights over the entire input power range. The phytochrome equilibrium ratio was calculated as 0.83 at full input power in the HPS environment. While there was a spectral shift associated with the decrease in input wattage, this shift occurred within a narrow waveband and resulted in only a slight decrease in the equilibrium ratio to 0.82 .

The MH lamp has a broader spectral output but also has a peak at $589 \mathrm{~nm}$ and another, $\approx 50 \%$ smaller, at $545 \mathrm{~nm}$ (Fig. 3). As observed with the HPS lamps, the primary peak dominance was diminished with a decrease in input wattage. The 589-nm peak in the MH environment was equal in height to the $545-\mathrm{nm}$ peak at $442-\mathrm{W}$ input. The 545-nm peak decreased very little as input power approached $428 \mathrm{~W}$, but peak dominance was shifted from 589 to $545 \mathrm{~nm}$. Two small peaks at shorter wavelengths, 360 and $440 \mathrm{~nm}$, retained absolute peak height as the input power was decreased. While a spectral change occurred as input power was decreased in the MH lamps, the phytochrome equilibrium ratio decreased only slightly, from 0.79 at full power to 0.78 at the lowest power settings.

When HPS and MH lamps were operated simultaneously (Fig. 4), the characteristic peaks of the HPS dominate as a result of the greater efficiency of the HPS and thus greater characteristic energy flux. PPF resulting from the combined environment exceeded 1200 $\mu \mathrm{mol} \cdot \mathrm{m}^{-2} \cdot \mathrm{s}^{-1}$ and was reduced to 550 $\mu \mathrm{mol} \cdot \mathrm{m}^{-2} \cdot \mathrm{s}^{-1}$ at minimum power. The phytochrome equilibrium ratio established in the combined HPS and MH environment was 0.85 at full power and increased slightly, to 0.87 , as the power was decreased. The unique spectral environment of the combined HPS and MH lamps resulted in a higher equilibrium ratio than that established under either individual lamp type. Differences between HPS and MH in electrical performance and quality shifts with decreasing input power also led to unique spectral environments and thus unique equilibrium ratios.

The variability among individual lamps ranged from $26 \%$ for $\mathrm{MH}$ to only $11 \%$ in the HPS for PPF and total energy flux (Table 1). Higher output of one MH lamp relative to the others tested resulted in the variability. The spectral output of individual lamps varied widely as well (Figs. 5 and 6). While there is variability in output and spectral quality of individual lamps, the phytochrome equilibrium ratio remains relatively unchanged. Morphological differences should not be expected to result from individual lamp spectral variability; however, test and selection of lamps based on similarity of energy output would significantly increase PPF and total radiant energy uniformity in the growth environment.

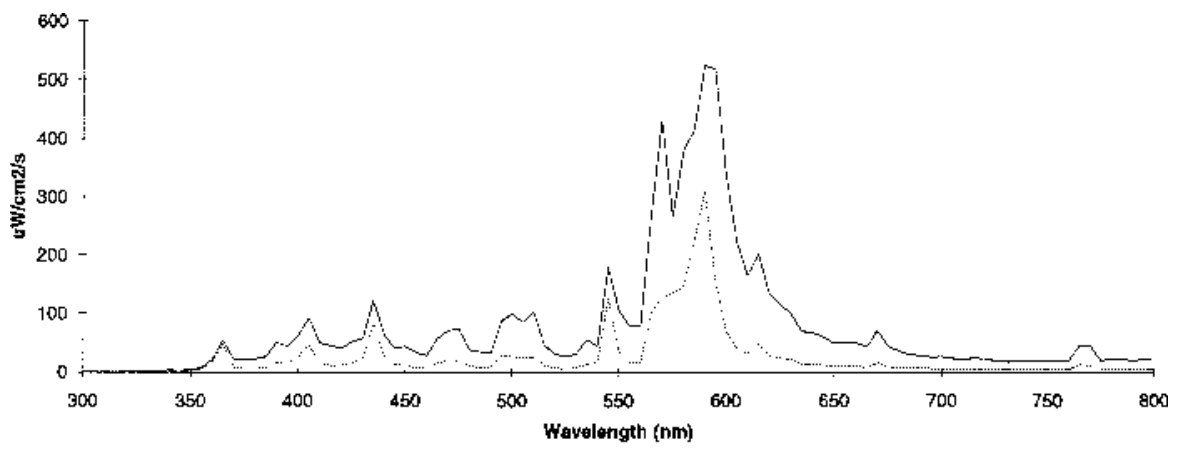

Fig. 4. Spectral quality resulting from simultaneous operation of metal halide (MH) and high-pressure sodium (HPS) lamps at full power (-) or minimum power (------). Maximum and minimum input power was 480 and $428 \mathrm{~W}$, respectively, for MH and 480 and $267 \mathrm{~W}$ for HPS.

Table 1. Photosynthetic photon flux (PPF), total energy flux, and phytochrome equilibrium ratio among three lamps of high-pressure sodium (HPS) and metal halide (MH). All lamps were $400 \mathrm{~W}$ and were operated at a input power set point of 55\%, which corresponds with 365 and $445 \mathrm{~W}$ for the HPS and MH lamps.

\begin{tabular}{lccc}
\hline \hline $\begin{array}{l}\text { Lamp } \\
\text { type and } \\
\text { sample }\end{array}$ & $\begin{array}{c}\text { Total } \\
\text { energy } \\
\text { flux } \\
\left(\mu \mathrm{mol} \cdot \mathrm{m}^{-2} \cdot \mathrm{s}^{-1}\right)\end{array}$ & $\begin{array}{c}\text { Phytochrome } \\
\text { equilibrium } \\
\text { ratio }\end{array}$ \\
\hline MH & & & $\left(\mathrm{mW}_{\mathrm{fr}}: \mathrm{P}_{\mathrm{tot}}\right)$ \\
1 & 241 & 6283 & 0.785 \\
2 & 200 & 5319 & 0.773 \\
3 & 369 & 9527 & 0.781 \\
Mean & 270 & 7044 & 0.781 \\
Standard deviation & 72 & 1800 & 0.005 \\
HPS & & & 0.848 \\
1 & 280 & 6268 & 0.864 \\
2 & 225 & 4970 & 0.855 \\
3 & 244 & 5421 & 0.855 \\
Mean & 250 & 5553 & 0.008 \\
Standard deviation & 28 & 659 & \\
\hline
\end{tabular}

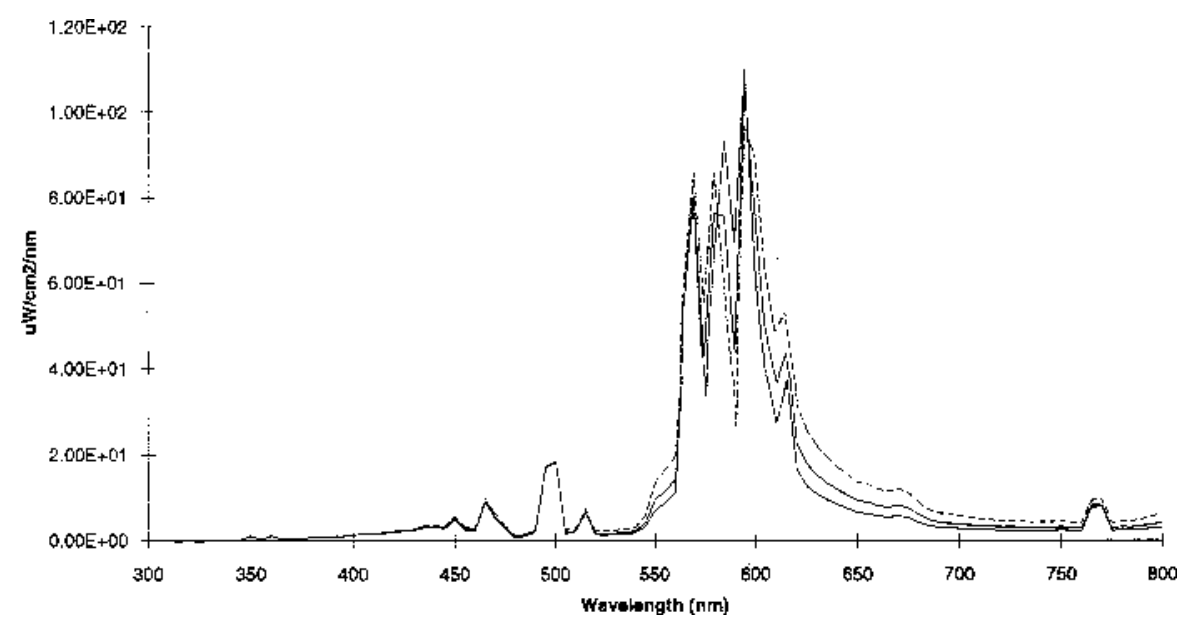

Fig. 5. Spectral variation among three high-pressure sodium lamps operated in the same fixture at 365-W input power.

\section{Conclusions}

Electronic dimming of HPS and MH highintensity discharge lamps using silicon rectifiers is an effective method for controlling PPF. Some spectral changes resulted from decreased input power to HPS and MH lamps; however, these changes were consistently limited to shifts in relative magnitude of the major peaks. We estimate the physiological and morphological consequences of these spectral shifts to be small, because the phytochrome equilib- rium ratio remained relatively unchanged in each of the environments tested. It appears that PPF can be reduced by $>50 \%$ using electronic dimming of HPS and MH lamps without significantly altering the spectral quality.

\section{Literature Cited}

Bubenheim, D.L., B.G. Bugbee, and F.B. Salisbury. 1988. Radiation in controlled environments: Influence of lamp type and filter material. J. Amer. Soc. Hort. Sci. 113:468-474.

HortScience, Vol. 30(5), August 1995 


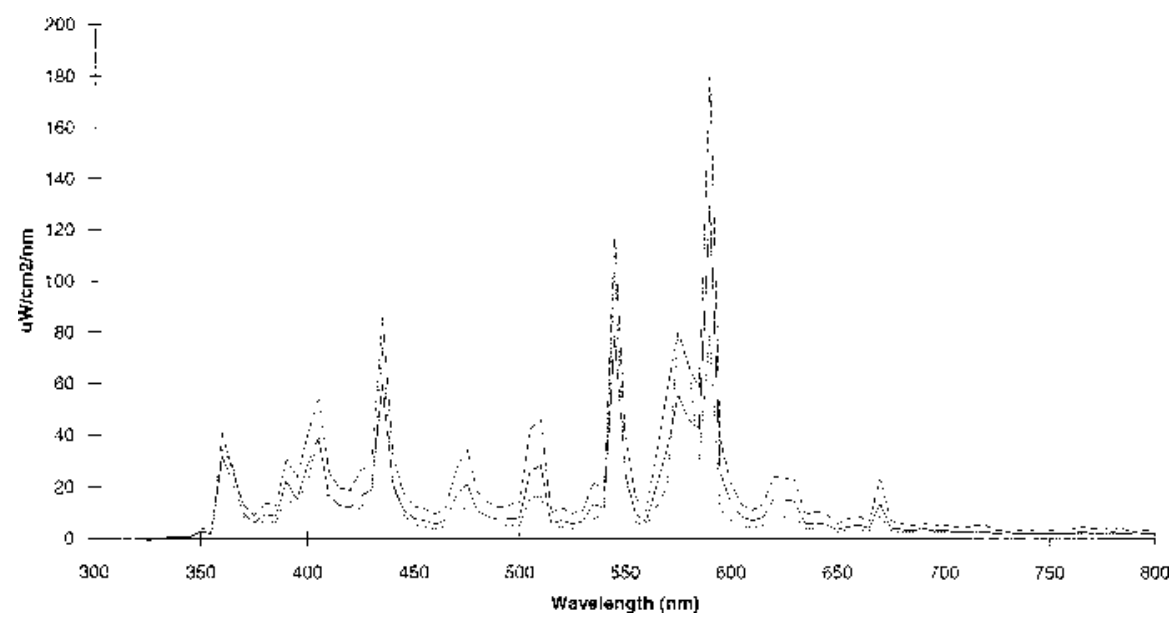

Downs, J.R. 1975. Controlled environments for plant research. Columbia Univ. Press, New York.

McFarlane, J.C. 1978. Light. In: R.W. Langhans (ed.). A growth chamber manual. Comstock Publishing Associates, Cornell Univ., Ithaca, N.Y.

Sager, J.C., W.O. Smith, J.L. Edwards, and K.L. Cyr. 1986. Use of spectral data to determine photosynthetic efficiency and phytochrome photoequilibria. Amer. Soc. Agr. Eng. Paper 86-3052.

Fig. 6. Spectral variation among three metal halide lamps operated in the same fixture at $445-\mathrm{W}$ input power. 